\title{
AQUI EU SOU CEGO, LÁ EU SOU VIDENTE:1 modos de ordenar eficiência e deficiência visual
}

\author{
Marcia Moraes* \\ Ronald João Jacques Arendt $t^{* *}$
}

\begin{abstract}
Situando-se no campo dos estudos de ciência, tecnologia e sociedade (CTS), o artigo investiga diferentes modos de ordenar a deficiência visual, isto é, os modos pelos quais a deficiência é feita em diferentes práticas, numa instituição especializada. São analisados documentos relevantes no campo da deficiência visual e alguns casos, o que permite problematizar a concepção de deficiência como deficit. $\mathrm{O}$ artigo sublinha que a relação entre corpo e deficiência visual não deve ser resumida a identificação da deficiência visual com a ausência de uma função sensorial. Através dos casos investigados, os autores propõem que se investigue a deficiência visual através de um corpo em ação, que se define por meio das conexões que estabelece com os mais díspares elementos, humanos e não humanos. O trabalho conclui apontando a relevãncia política de multiplicar as versões de eficiência e deficiência visual, de modo a subeverter a concepção de deficiência como deficit.

PALAVRAS CHAVE: deficiência visual, corpo em ação, modos de ordenar, materialidades, socilaidades.
\end{abstract}

\section{MODOS DE ORDENAR EFICIÊNCIA E DEFICI- ÊNCIA: delimitando as questões}

Nos últimos anos, temos nos dedicado a realizar uma pesquisa ${ }^{2}$ com pessoas com deficiência visual. O objetivo é seguir os modos pelos quais a cegueira existe, os modos pelos quais ela vai se constituindo em arranjos bastante heterogêneos que articulam humanos a não-humanos, materialidades a socialidades (Law; Mol, 1995). Situamos esta pesquisa na esteira daquelas empreendidas por Foucault $(1972,1987,2000)$ e, posteriormente, pelo campo de estudos chamados CTS - ciência, tecnologia e sociedade. ${ }^{3} \mathrm{O}$ que nos faz situar este

* Doutora em Psicologa Clínica. Professora do Departamento de Psicologia da Universidade Federal Fluminense. Bolsista de Produtividade em Pesquisa - CNPq.

Campus do Gragoatá. Bloco O. $2^{\circ}$ andar. Niterói. Rio de Janeiro.mazamoraes@gmail.com

* * Doutor em Psicologia. Professor do Departamento de Psicologia Social e Institucional da Universidade do Estado do Rio de Janeiro. arendt.ronald@gmail.com

${ }^{1}$ Vidente é o termo utilizado no campo da deficiência visual para fazer referência às pessoas que enxergam.

${ }^{2}$ Para ler mais sobre os resultados deste trabalho conferir: Moraes, 2006, 2007, 2008.

${ }^{3} \mathrm{O}$ campo de estudos CTS é bastante vasto, reúne pesquisas em diversas áreas. Nesse campo, a noção de rede é afirma- trabalho nesse domínio é, de um lado, a concepção bastante ampla de que a deficiência não é um objeto dado, é antes algo cuja existência depende de certas condições de possibilidades que se realizam materialmente. De outro lado, seguindo as pistas dos estudos CTS, interessa-nos acompanhar os modos por meio dos quais a deficiência existe, é feita em certos arranjos sociomateriais locais situados, ou seja, visamos a seguir os diferentes modos de ordenamento da deficiência visual. Em última instância, podemos dizer que os estudos CTS nos permitem formular algumas questões no campo da deficiência visual que nos parecem bastante pertinentes: se, desde os trabalhos de Foucault $(1972,1987,2000)$ sobre o biopoder, sabemos que a concepção de normalidade é construída historicamente em certos arranjos materiais, perguntamos onde, quando, em que práticas, em que materialidades certa concepção de normalidade existe? Com outras palavras, se a deficiência não é

da como uma ontologia de geometria variável, que se refere a um processo ativo de associação, no qual as entidades emergem. Assim, afirma-se que a realidade é construída, é efeito de tal processo de associação ativa. Para mais informações sobre esse campo de estudos, ver Law e Hassard, 1999; Latour, 1994; Moraes, 2004, Law, 2008. 
um dado universal, feito de uma vez por todas, onde, como, em que práticas ela é articulada? Lançar o olhar de pesquisador para certas práticas locais e situadas, entendendo que é justamente nelas e por elas que uma realidade é feita, eis aí uma fortíssima contribuição dos estudos CTS para as nossas pesquisas (Mol, 2002, 2008; Moser, 2006, 2005, 2000; Law 2004) .

Falar em modos de ordenamento da deficiência visual nos engaja num estudo que investiga como e em que formas sociomateriais a deficiência é feita. Assim, a deficiência não é o que uma pessoa é, nela mesma. Tampouco alguma coisa que é produzida por um social que, de fora, do exterior, sobredetermina o indivíduo. Lidar com modos de ordenamento implica tomar o social não como substantivo, mas como verbo, como um processo precário, local, situado; implica ainda colocar o foco tanto na heterogeneidade material quanto na multiplicidade e na complexidade de tais ordenamentos. Nas palavras de Mol,

... modos de ordenamento tornam o discurso múltiplo e móvel. 'Modos’ é um plural: convida a uma comparação dos diferentes modos de pensar e agir que coexistem num único tempo e espaço. Ordenamento, derivado de um verbo mais do que um substantivo, evoca um processo: sugere que a atividade de ordenar envolve um esforço contínuo que pode sempre falhar (2008, p.9).

Assim, neste trabalho, seguiremos alguns modos de ordenar a deficiência visual com a finalidade de investigar as diferentes articulações de eficiência e deficiência que vão sendo produzidas, feitas em alguns arranjos bastante heterogêneos. Trata-se de uma investigação sem dúvida situada, localizada em certas práticas. Não pretendemos com isso produzir uma verdade última sobre o que é a deficiência visual. Ao contrário, o que visamos com este trabalho é a interferir numa certa versão de deficiência como falta, como déficit, como desvio por relação a uma normalidade corporal a ser alcançada. Visamos ainda, como Mol (2008), a evitar qualquer concepção de normalidade nãomarcada, isto é, não-atrelada a suas condições de produção sociomateriais. Afirmar a deficiência como alguma coisa que existe apenas num individuo, ou que a deficiência é provocada por um corpo defeituoso, lesionado (Santos; Diniz, 2009; Diniz; Medeiros; Squinca, 2007; Martins, 2006a, 2006b, 2006c), é, ao mesmo tempo, conceber que isso não tem nada a ver conosco, os nãodeficientes ou eficientes. A falta de eficiência, de capacidade de agir, uma vez atrelada a um corpo individual, defeituoso, faz também existir a versão da normalidade desengajada, desencarnada, nãomarcada - para retomar a expressão de Mol (2008). Uma versão de deficiência que está, portanto, articulada a certa versão de normalidade: a normalidade desengajada, desencarnada, eficiente. São como que duas faces de uma mesma moeda: a um corpo não-eficiente corresponde uma normalidade desencarnada, sem condições corporais, materiais, de existência. Os arranjos sociomateriais que produzem corpos eficientes são, nesse último caso, invisibilizados (Moser, 2005).

É justamente nessa medida que Moser (2005, 2000), ao estudar as tecnologias assistivas, levanta questões com relação tanto a essa concepção de que a deficiência é algo que se localiza num corpo individual, quando com relação à normalidade desencarnada que lhe é coextensiva. Assim, ao entrevistar uma pessoa que precisa de um dispositivo técnico para se comunicar, já que sua fala foi comprometida por um acidente vascular cerebral, Moser se dá conta de que, quando esse dispositivo falha, é aquela pessoa que falha em se comunicar conosco, os eficientes. Ninguém se pergunta, diz a autora, se não somos nós que não conseguimos falar com aquela pessoa. Mas é o contrário disso o que se passa: o fracasso do dispositivo de fala, torna visível a ineficiência daquela pessoa, a sua dependência de certas condições materiais para se comunicar conosco. É nesse momento, aí, nessa falha, que aquela pessoa é ineficiente, deficiente, enquanto seu interlocutor é ordenado como eficiente, desengajado, desencarnado de qualquer condição material que lhe permita falar, pensar, agir.

Com a escrita deste trabalho, pretendemos interferir nesse cenário, para fazer proliferar as 
versões e distribuições de eficiência e deficiência que são produzidas em certas práticas. Apostamos na variação e na multiplicidade de arranjos e ordenamentos que articulam eficiência e deficiência, como condições de ação que são necessariamente situadas e encarnadas. E, para sermos fiéis a essa aposta, nos posicionamos no encalço de certas práticas, situadas numa instituição voltada para pessoas com deficiência visual, digamos, a Instituição X. Como e de que modo eficiência e deficiência vão sendo distribuídas, ordenadas em certas práticas de uma instituição especializada, localizada na cidade do Rio de Janeiro e que desenvolve ações voltadas para a reabilitação da pessoa com deficiência visual? Quais são os modos de ordenar eficiência e deficiência que ali aparecem? Como tais modos se articulam? Que relações são estabelecidas entre corpo e deficiência visual? Essas são algumas das questões que nos incitam a escrever este artigo.

\section{CENA 1: \\ modos de ordenar a deficiência visual: $80 \%$ de que mesmo?}

Um importante local de ordenamento da deficiência está nos textos, nos documentos oficiais que estabelecem diretrizes para a educação e (ou) reabilitação das pessoas com deficiência visual e que são referências necessárias na formação dos profissionais da Instituição X. Nos últimos anos, o tema da inclusão das pessoas com deficiência conquistou a agenda política no Brasil e em outros países. Em 2001, a Secretaria de Educação Especial do Ministério da Educação do Brasil (MEC) publicou um documento, intitulado Programa de capacitação de recursos humanos do ensino fundamental: deficiência visual. Trata-se de uma edição de textos que orientam as ações de professores e profissionais que trabalham com pessoas cegas e com baixa visão e são referências necessárias no campo da educação e da reabilitação da pessoa com deficiência visual no Brasil. Em um trecho desse documento, lemos o seguinte:
É sabido que a visão transmite ao indivíduo informações com rapidez e precisão, antecipa e coordena os movimentos e ações e responde por $80 \%$ do relacionamento do indivíduo com o mundo. Portanto, são muitas e significativas as implicações da deficiência visual na integração do indivíduo, visto que a ausência de visão prejudica a compreensão do mundo, interfere na qualidade de troca e solicitação com o meio, causa, muitas vezes, a privação de vivências, limitação de movimentos e interfere na orientação espacial (BRASIL, 2001 p.49, fascículo V). ${ }^{4}$

A afirmação de que a visão responde por 80\% do relacionamento do indivíduo com o mundo é apresentada como fato consumado, como se esses mágicos $80 \%$ não tivessem também sido produzidos em certas práticas, fazendo uso de todo tipo de dispositivos de inscrição ${ }^{5}$ (Latour, 1987, 2001). Nesse trecho do documento, tal referência percentual é apresentada longe de suas condições de produção, como um dado neutro, "cientificamente comprovado". Se $80 \%$ do relacionamento com o mundo está atrelado à visão, cabe à pessoa com deficiência visual ficar com os $20 \%$ que restam, o que, sem dúvida, faz existir uma versão de deficiência visual como uma enorme desvantagem. Para Latour (1987), um dado como esse, apresentado assim, sem aspas, sem nenhuma outra referência, é uma caixa-preta, ou seja, é algo tomado como não-problemático, não-controverso. Pois justamente, o convite que o autor nos faz é o de investigar não os fatos prontos, estabilizados, mas o processo de construção e fabricação de tais fatos. Processos locais, situados, fundados numa "amarração" heterogênea que reúne coisas a pessoas e que exige esforço e trabalho para se manter coesa. Remontar dos fatos aos processos é retomar a controvérsia que multiplica e alarga as possíveis versões de mundo. É, conforme diz o autor, partir do

${ }^{4}$ Neves (2010) apresenta uma interessante discussão sobre esse documento do MEC.

5 "Chamarei de instrumento (ou de dispositivo de inscrição) qualquer estrutura [...] que possibilite uma exposição visual de qualquer tipo num texto científico [...] a estrutura possibilita uma inscrição que é usada como camada final num texto científico. Um instrumento, nessa definição, não é qualquer estrutura que tenha um mostrador onde se possa fazer uma leitura. Um termômetro, um relógio, um contador Geiger, todos esses aparelhos possibilitam leituras, mas não são considerados instrumentos, porquanto essas leituras não são usadas como camadas final em artigos técnicos" (Latour, 1987, p.112-113). 
mundo frio dos fatos e das caixas-pretas, ao mundo quente das controvérsias.

Nesse sentido, é preciso sublinhar que um texto não é "apenas um texto", mas se trata de uma materialidade que engendra e se articula com socialidades (Law; Mol, 1995): as práticas dirigidas às pessoas com deficiência visual retomam a concepção de deficiência visual pautada no citado referencial de porcentagem. Odocumento que analisamosébase e referência na formação de profissionais da área da deficiência visual. Logo, não se trata apenas de um texto, mas de certo modo de ordenar eficiência e deficiência que corrobora e faz existir uma versão de deficiência como incapacidade e que se conecta com outras práticas, outras materialidades, outras socialidades, e é justo nessa medida que ele atua na direção de fazer expandir a versão de deficiência como falta provocada pela ausência de um sentido. E, atrelada a essa concepção de deficiência, há uma concepção de que a eficiência corresponde aos $100 \%$ de relacionamento com o mundo que uma pessoa com visão e com os demais sentidos ativos pode alcançar. Kastrup, Carijó e Almeida (2009) também problematizam esse dado estatístico que circula amplamente no campo da deficiência visual e que é apresentado como um dado neutro, objetivo, que, conforme os autores, sustenta uma concepção de que conhecer é apenas e tão somente processar informações oriundas de um mundo previamente dado. Concordamos com os autores e, mais do que isso, o que nos parece relevante é que tal afirmação pré-forma uma distribuição de eficiência e deficiência segundo a qual a pessoa com deficiência visual é marcada pelo déficit e pela falta de acesso às informações provenientes do mundo.

Mas será que essa informação percentual existe isoladamente no documento do MEC? A fim de seguir os rastros que esse dado produz, buscamos $^{6}$ localizar as suas condições de produção, na

${ }^{6}$ Utilizamos, para isso, a ferramenta Google e o Google Acadêmico com a busca por: "deficiência visual $80 \%$ das informações são visuais”. Realizamos buscas também na Revista Brasileira de Oftalmologia com as palavras: "deficiência visual", "cegueira". Nesse periódico, encontramos alguns artigos sobre deficiência visual. Em nenhum deles havia a menção às condições de produção do dado de que recebemos pela visão $80 \%$ das informações do mundo. tentativa de desvendar em que práticas e com que formas de registro esse dado foi produzido e "achado". Quanto a isso, nossas buscas foram mal sucedidas. Foram, no entanto, bem sucedidas porque indicaram que a afirmação desse valor percentual é retomada em vários textos e sites que tratam da deficiência visual, muitos deles, sem dúvida, em prol da inclusão da pessoa cega e com baixa visão. O interessante é que, em nenhum dos textos e sites que consultamos, há a indicação acerca do modo como este dado foi produzido. Vejamos alguns exemplos do que encontramos:

Das informações visuais que recebemos, $80 \%$ chegam pela via óptica e são integradas com informações advindas de outros canais sensoriais, que podem ser estimulados. Este conjunto favorece e propicia o desenvolvimento global da criança. Estas informações visuais não só nos capacitam como também reforçam as habilidades de coordenação de movimento (Lopes; Quitadai; Okai, 2004, p.159).

Considere-se que o sistema visual detecta e integra $80 \%$ dos estímulos no ambiente. [...] Esses alunos [com deficiência visual] recebem e organizam a informação no processo de apropriação do conhecimento e construção da realidade em um contexto impregnado de padrões de referências e experiências eminentemente visuais que os colocam em situação de desvantagem (Sá; Campos; Silva, 2007, p.14).

A visão é um dos mais importantes meios de comunicação, sendo que cerca de $80 \%$ das informações que recebemos são obtidas por seu intermédio. E, portanto, importante para o pleno desenvolvimento pessoal e relacionamento do indivíduo com o meio ambiente circundante (Ministério da Saúde, 19947) (Lopes; Barbosa; Marques; Lino; Morais, 2003, p.55).

Alguns especialistas dizem que cerca de $80 \%$ da informação que chega ao cérebro é veiculada através do sentido da vista; outros se limitam a afirmar que através deste sentido passa mais informação do que por todos os outros sentidos juntos. Seja como for, ninguém duvida de que, dos cinco sentidos, é o da vista que desempenha o papel mais importante no desenvolvimento equilibrado do indivíduo, permitindo-lhe socializar-se através da imitação. É esta dominância que leva à constatação de que "a vida se apresenta organizada por quem vê, para os que veem”, que encontramos tantas vezes em alguns estudiosos na matéria (Silva, 2005, p.1).

Não tivemos acesso a esse documento do Ministério da Saúde citado pelos autores. Consideramos, sem dúvida, que ele deve ser consultado, para levarmos adiante o tipo de análise que fazemos aqui. 
Chama a atenção o fato de que todos esses textos retomam de modo acrítico um dado estatístico, como se ele fosse autoevidente e autoexplicativo. Logo, tal dado não é alguma coisa que ocorre isoladamente, mas sim certo modo de pré-formar a deficiência visual que paradoxalmente faz existir uma versão de deficiência como falta de eficiência. Se falamos aqui em paradoxo é para sublinhar que os textos por nós consultados apresentam argumentos em prol da inclusão da pessoa com deficiência visual, em favor de uma sociedade mais justa, mais igualitária. O discurso que os caracteriza é o da igualdade dos direitos. O que nos parece paradoxal, já que a defesa da inclusão é feita a partir de um argumento que faz existir uma enorme assimetria entre aqueles que são eficientes - que acessam 100\% das informações do mundo - e os outros, eles, os não-eficientes, que só acessam 20\% das informações.

Essa forma de distribuir eficiência e deficiência invisibiliza aquilo que Canguilhem chamava de normatividade da vida, isto é, a capacidade que todo vivo tem de instituir normas locais e parciais que lhe permitam viver. Foi Canguilhem (1976) quem, nos meados do século XX, clamava por uma filosofia da vida que fosse mais condizente com essa característica do vivo. Viver é diferir, e não é senão a capacidade de variar. Canguilhem (1976) sinalizava que a normalidade estatística perde de vista essa errância da vida. A curva normal não se confunde com a normatividade do vivo e não faz senão produzir desvios, déficits por relação aos padrões tomados como normais. Ao clamar por uma filosofia que estivesse mais afinada com as exigências da vida, o filósofo francês nos coloca diante do desafio de retomar uma filosofia afinada com a diferença e a errância, que são próprias ao vivo. Nesse ponto, parece-nos extremamente pertinente afirmar a contemporaneidade de suas contribuições e a sintonia entre elas e muitas das discussões que se travam hoje no campo dos estudos CTS.

Retomar as práticas nas quais a deficiência é feita, apostar que existem múltiplas versões nos modos de ordenar eficiência e deficiência, problematizar qualquer concepção de normalidade não-marcadaé, de algum modo, reverberar e expandir o sentido de normatividade da vida, proposto por Canguilhem.

\section{CENA 2: \\ Variações do ver e do não ver: aqui eu sou vidente, lá eu sou cego ${ }^{8}$}

A fim de seguir os modos de ordenar a deficiência visual, realizamos algumas entrevistas e observações com pessoas com deficiência visual que tinham algum tipo de vínculo com a Instituição X, seja como alunos regulares da escola - no segmento do ensino fundamental -, seja como alunos do setor de reabilitação dessa mesma instituição. Apresentamos, a seguir, alguns extratos dessas entrevistas realizadas nos anos de 2007 e 2008 com os alunos do ensino fundamental daquela instituição.

Diadorim $^{9}$ é um menino de 15 anos, morador da Rocinha; ele tem baixa visão e fica na escola de segunda a sexta-feira, em regime de internato. Ele lê e escreve em tinta, com as fontes ampliadas, e aprendeu a ler o Braille com os olhos e não com os dedos. Para fazer isso, ele coloca os olhos encostados no papel com o texto em Braille e, lentamente, vai deslizando o rosto sobre o papel, até ler o que está escrito. Comentando sobre sua vida naquela instituição de ensino, ele afirma:

Eu queria morar aqui [na instituição], sabe por quê? Porque aqui eu sou vidente, todo mundo me respeita. Aqui eu sou 'o cara'. Lá na Rocinha eu sou cego e todo mundo fica zoando de mim, fica falando coitadinho do ceguinho, dando cascudo .

Em outra entrevista, Arlequim, com 15 anos e que ficou cego há 2 anos, em decorrência de uma doença progressiva, comenta:

As pessoas acham que cego é cego, é tudo igual. Mas não tem essa. Cada um é de um jeito. Eu sou cego, não vejo mais o Chaves na televisão, mas

${ }^{8}$ Para outras discussões acerca dos casos que são apresentados a seguir, ver Moraes e Arendt, 2010.

${ }^{9}$ A fim de preservar o anonimato dos entrevistados todos os nomes das pessoas que entrevistamos foram trocados. 
percebo luz e sombra, sei quando a janela está aberta ou fechada. Eu faço um monte de coisas.

Em outra oportunidade, esse mesmo menino comenta:

Antigamente eu via as coisas. Depois que eu deixei de ver, meus amigos mudaram. Aqui na escola os alunos se dividem: cego anda com cego, vidente anda com vidente. Vidente vive pregando peça nos cegos. Eu acho isso errado .

E ainda, na fala de Wellington de 18 anos, com cegueira adquirida há 2 anos em função de uma doença progressiva:

As pessoas acham que só porque a gente é cego a gente não pensa, não tem desejos, não tem uma vida com sonhos, como todo mundo. Eu ando na rua com minha mãe, e as pessoas, ao invés de falarem comigo, falam só com ela. Só porque o olho é perto do cérebro, as pessoas acham que o cego tem problema na cabeça! Quando a gente é cego, a gente apura a pele toda!

O que essas falas apontam é para arranjos distintos da deficiência visual. Articulada com o espaço da escola, com o pátio, com as salas de aula, Diadorim nos fala de uma distinção muito peculiar entre o que existe na escola - onde ele é 'o cara' - e o que se passa na Rocinha, onde ele é cego. Ora, o que nos parece estar em jogo aí são modos de ordenar o ver e o não ver que não se confundem com a presença ou ausência de um sentido, a visão, gravada, inscrita num corpo isolado. Em última instância, parece-nos que há aí certa distribuição da eficiência e deficiência que está diretamente articulada a tais materialidades (quais sejam, a escola, o pátio, a Rocinha). Se seguirmos as normatividades, no sentido da instituição de normas de vida locais e parciais, podemos dizer que as falas de Diadorim, Arlequim e Wellington apontam para as astúcias, as artes de viver sem ver - o que justamente fica oculto se seguirmos apenas os traços da normalidade estatística. O pátio da escola, a Rocinha, os colegas, a pele toda, tudo isso no diz algo sobre o não ver em ação, situado, localizado nas vidas e nos corpos daqueles que vivem sem a visão. E é aí que pulsa a variação dos ordenamentos da defici- ência e da eficiência.

Investigar o não ver em ação implica seguir as muitas conexões que cotidianamente são feitas entre corpo e deficiência visual. Nas falas que citamos acima, tal conexão é sublinhada. Corpo-pátio, corpo-Rocinha, corpo-cascudo, corpo-luz-sombra, corpo-Chaves, corpo-pele-toda... E justamente o que parece ser problematizado é a versão de deficiência atrelada a um corpo individual, isolado - "só porque o olho é perto do cérebro...". Falamos em corpo para indicar que refazer as distribuições de eficiência e deficiência, interferindo na versão da normalidade não-marcada, implica seguir as pistas que são abertas por Diadorim, Arlequim, Wellington e tantos outros. Trata-se de tomar o corpo não como objeto dado, mas como algo que é feito, tecido, através das conexões com o mundo (Latour, 2002). Não se trata nem de tomar o corpo como objeto, nem como corpo vivido, mas como o corpo que nós fazemos (Mol; Law, 2003), isto é, um corpo que é construído pelas afetações do mundo e que se define por meio das conexões com os mais diversos e heterogêneos materiais. Ter um corpo é aprender a ser afetado, movido e efetuado pelo mundo (Latour, 2002). Um corpo é, portanto, uma configuração complexa, um agenciamento que liga, articula e conecta humanos e não-humanos. Manter um corpo coeso e articulado exige esforço e trabalho - é o que cada um de nós faz cotidianamente. Assim, longe de tomar a deficiência visual como alguma coisa que se define exclusivamente pelo valor percentual de apreensão das informações do mundo, seguimos as pistas dos modos como o corpo e a deficiência visual vão sendo articulados e conectados no cotidiano.

Uma das versões de cegueira que Diadorim narra - o cego que leva cascudo, é "zoado" e de quem todos falam que é coitado - encena uma cegueira como desgraça e incapacidade. São muitas as formas de traçar a história dessa versão de deficiência visual. Martins (2006a, 2006b, 2006c) refaz o percurso histórico dessa concepção de cegueira apontando para a sua apropriação, na modernidade, pelo idioma da biomedicina e dos parâmetros estatísticos de normalidade. $\mathrm{O}$ autor 
indica que, se, na modernidade, a cegueira passou a ser encarada como um acontecimento "natural" e não mais místico, foi ao preço de ser apreendida como não eficiência - como incapacidade, tragédia, infortúnio.

A narrativa de Diadorim aponta que, no cenário da comunidade em que ele reside, a cegueira é pré-formada por comparação a um parâmetro de normalidade que também circula nas e é constituído pelas práticas cotidianas. Os tais 20\% de mundo que restariam aos cegos talvez estejam, de algum modo, presentes naquele cenário.

\section{CENA 3: \\ Geórgia, as sucatas e o sorriso: corpo e deficiência visual}

Geórgia chega à Oficina de Experimentação Corporal ${ }^{10}$ pela primeira vez, trazida pela mãe. Ela tem 46 anos. Ficou cega aos 16 anos, em decorrência de uma doença progressiva que a acompanhava desde muito criança. Não aprendeu a ler, nem a escrever, porque, segundo nos disse sua mãe, a doença nos olhos dificultava o processo de aprendizagem e, depois de ter ficado definitivamente cega, passou a sair pouquíssimo de casa, já que sua mãe trabalhava fora todos os dias, saindo pela manhã e retornando para casa já à noite. Geórgia não anda na rua sozinha e se locomove sempre com a ajuda de alguém. Os dedos das mãos são encolhidos. Segundo a mãe nos informa: "ficaram assim porque ela se mexia muito pouco”. Geórgia comenta que gosta de ouvir música, Lulu Santos, ela diz. Fala ainda que, em casa, ficava muito tempo sentada no sofá, ouvindo música, que era a

${ }^{10}$ A Oficina de Experimentação Corporal faz parte do Projeto de Pesquisa Perceber sem Ver, por mim coordenado. Trata-se de uma atividade de intervenção voltada para pessoas adultas com deficiência visual adquirida e que estão vinculadas ao setor de Reabilitação da Instituição X. A Oficina visa a promover atividades lúdicas de consciência e sensibilização corporal com as pessoas que acabaram de cegar. A metodologia desse trabalho é baseada na concepção de que pesquisar é uma ação engajada, que se faz com outros e não sobre outros. Assim, as ações realizadas são partilhadas e construídas junto com os participantes das Oficinas. Para saber mais sobre esse trabalho, ver Moraes (2010, 2008, 2007, 2006); Moraes e Arendt (2010); Moraes e Kastrup (2010). única coisa que tinha para fazer.

Conversamos com as professoras que ensinam Geórgia a usar a bengala. Elas comentam que, antes de aprender a usar a bengala, Geórgia precisa saber se movimentar, porque tem "o corpo todo duro, não tem traquejo”. Dizem que acham difícil trabalhar com Geórgia porque é insegura, tem medo das coisas e nunca andou sem a ajuda de alguém que enxergasse.

Em um dos encontros da Oficina de Experimentação Corporal, as coordenadoras propuseram uma atividade que envolvia movimentar-se no espaço a partir dos sons que eram emitidos. Assim, quando um som vinha do canto direito da sala, os participantes da Oficina deveriam se mover nessa direção; em seguida, outro som, mais alto vinha da porta de entrada da sala, e eles deveriam se encaminhar para essa direção, e assim por diante, num ritmo proposto inicialmente de modo lento e que ia aumentando, tornando-se mais acelerado, com o passar do tempo. ${ }^{11}$

Durante essas atividades, Geórgia, sempre se apoiando em alguém, não distinguia de onde vinha o som e ficava esperando ser guiada, levada até o ponto de origem do som. Parecia-nos que Geórgia articulava-se pouco com tais sons - em sua experiência com a música, ela ficava sentada e o som vinha sempre do mesmo lugar. Ela nos relatava que achava difícil perceber a direção do som e dizia que não sabia direito como fazer isso. Comentava que as mudanças de direção também eram difíceis de ser acompanhadas e que, além do mais, tinha medo de andar sem se apoiar em alguém. Ela comenta que preferia esperar que alguém a guiasse até o local de onde vinha o ruído. Pergunto se, quando anda na rua não, é também necessário perceber a origem do som. Ela diz que não, porque está sempre com alguém que a guia.

Em outra sessão da Oficina, ainda seguindo a mesma temática, os sons são propostos pelos participantes do grupo e não mais pelos coorde-

${ }^{11}$ Ressaltamos que tais atividades foram propostas a partir de impasses surgidos em encontros anteriores da Oficina, os quais apontavam que uma das questões fundamentais para quem perde a visão era reconhecer a direção do som e orientar-se no espaço a partir desse referencial. 
nadores. Com latas e outras sucatas nas mãos, cada participante tem a sua vez de comandar a Oficina, fazendo uma sequência ritmada de sons que devia ser retomada pelos demais com palmas. Geórgia assume espontaneamente o comando. Faz uma série de sequências sonoras. Novas articulações, novos efeitos. Geórgia, ao invés de ser guiada, guiava. Apropriou-se das sucatas e tornou-se regente, ${ }^{12}$ articulava-se com o som, com o grupo, com suas mãos - adquiria o seu corpo (Latour, 2002). Quanto mais sons e ritmos ela produzia com as sucatas, mais as sucatas faziam seu corpo moverse, afetar-se, transformar-se. Seu rosto ficou vermelho e, pela primeira vez, vimos os seus dentes, que ficaram à mostra num farto e largo sorriso, que logo se tornou uma gargalhada. As sucatas, os sons e o grupo faziam existir ali um novo arranjo do não ver. Arranjo heterogêneo, instável. Nesse arranjo, os limites entre eficiência e (de)ficiência eram redistribuídos por vários atores: as sucatas faziam Geórgia reger, Geórgia regia e movia o grupo. Nesse modo de ordenar a cegueira, a conexão com a sucata, com o som, com o grupo, conta. A capacidade de agir e a subjetividade se tornam possíveis nessas relações encarnadas, nesses arranjos. E Geórgia agia e fazia outros agirem. As sequências sonoras que ela criava eram complexas, longas e ritmadas. Talvez efeitos das músicas que por tanto tempo ouviu sentada no sofá.
Interessante notar que, nesses dois episódios, a distribuição da eficiência e da (de)ficiência parece ocorrer de modo distinto. No primeiro caso, a articulação de Geórgia com os sons e com o grupo parece fraca, enquanto a articulação com o guia se faz forte e é a que prioritariamente parece produzir alguma diferença. No segundo caso, as sucatas e a sequência de sons são articulações fortes no sentido de fazer existir certo modo de ordenar eficiência e (de)ficiência, o que implica uma redistribuição: de guiada, Geórgia passa a ser guia. A cegueira, que até então era ordenada como imobilidade - não anda sozinha, não sai de casa -, ordena-se de outro modo. O que tais ordenamentos colocam em cena? Como eles se articulam?

${ }^{12}$ Agradecemos a Carolina Manso por essas observações.
Esses ordenamentos fazem existir modos distintos de cegueira, que se sobrepõem e se articulam, na medida em que eficiência e (de)ficiência se distribuem por diferentes materialidades e socialidades. Há uma passagem entre esses modos de ordenar a deficiência e mais: em tais ordenamentos, materialidades e socialidades articulam-se diferentemente.

É nesse sentido que Law (1999) afirma que a deficiência está relacionada à questão política, que consiste em definir quem e o que conta nos coletivos sociomateriais. O que está em jogo é definir quem conta ou não como ator, como agente capaz de agir, de produzir efeitos. Desse modo, o foco não está em partir, a priori, da distinção eficiência versus (de)ficiência, mas, antes, em seguir os arranjos locais nos quais tais distinções vão sendo construídas.

Concordamos com Moser, quando afirma que:

... há diferentes modos de ordenamento feitos no cotidiano das vidas das pessoas, e as pessoas deslizam e mudam entre elas. Elas são, desse modo, feitas em múltiplos e mutáveis modos. Mas não basta dizer isso. A questão urgente é o que isso significa... Isso implica que as pessoas estão livres para escolher e para se mover à vontade entre modos de ordenamento da deficiência, ou pelo menos que há um jogo entre elas, e logo espaço para resistência e (alguma) ação? (2006, p.685).

Em outras palavras: que diferença a diferença faz?

\section{CONSIDERAÇÕES FINAIS}

Neste artigo, acompanhamos diferentes modos de ordenar a deficiência visual. Seguimos alguns rastros do ordenamento da deficiência atrelada a um dado estatístico, cujas condições de produção são invisibilizadas. Seguimos, ainda, algumas conexões dessa versão de deficiência com outras que são feitas nas práticas cotidianas em uma Instituição especializada. Nesse cenário, parece-nos pertinente levantar algumas perguntas: - Como, onde e de que modo pretendemos interfe- 
rir nesse processo de ordenamento da deficiência visual?

- Mais uma vez, retomamos a pergunta que formulamos anteriormente: que diferença a diferença faz?

- Que diferença os estudos CTS fazem nesse campo?

Certamente, desde os trabalhos de Foucault

(1972, 1987, 2000), muitas das pesquisas no campo da deficiência visam a desnaturalizá-la, isto é, a apontar de que modo o discurso da normalização se constrói e se materializa em práticas, corpos, instituições. A aposta que fazemos nos estudos CTS nos permite recolocar a questão da deficiência explorando os diferentes modos por meio dos quais a deficiência é feita. Ou seja, se entendemos que ser deficiente não é algo que uma pessoa é, mas algo que ela se torna, o objetivo da pesquisa passa a ser acompanhar os modos pelos quais eficiência e deficiência são distribuídos, ordenados, num conjunto de materialidades, de práticas que não cessam de produzir ordenamentos muito singulares da deficiência. O que interessa à pesquisa é explorar as alternativas, investigar os modos locais nos quais tais ordenamentos ocorrem. Em última instância, podemos dizer que as ferramentas dos estudos CTS nos permitem colocar de novo a velha questão do que é ser humano, num marco certamente bastante distante de qualquer humanismo. Nesse sentido, ser humano não é mais do que esse arranjo local, provisório, de materialidades e socialidades. A subjetividade e o corpo são efeitos desses arranjos locais. Assim, a aposta pragmática dos estudos CTS é de que, na prática, não há apenas um modo de ordenamento da deficiência, mas vários. Diferentes modos que se articulam, se sobrepõem, se contradizem. A multiplicidade é, assim, um caminho para pensarmos alternativas, formas de resistir ao ordenamento da normalização, que faz da deficiência um déficit. Isso porque a introdução da diferença e de novas alternativas no cenário das investigações no campo da deficiência torna visível o que a normalização invisibiliza e desarticula.

Abrir as condições de possibilidade da deficiência implica seguir os diferentes modos nos quais a deficiência se ordena, com condições materiais e sociais distintas, diferentemente articuladas. Assim, as realidades criadas permanecem abertas, precisamente porque são ordenadas a cada momento, em cada situação. Nesses locais, as pessoas são eficientes e deficientes segundo uma distribuição de agência, que é sempre encarnada, materializada numa série de atores. Nesse sentido, "todos os sujeitos, eficientes e (de)ficientes, são fluidos e abertos, constantemente, movendo-se entre posições subjetivas e articulando estes movimentos de diferentes modos" (Moser; Law, 2001, p.9).

Os estudos CTS são ferramentas poderosas para resistir à normalização. Como pesquisadores, interessa-nos interferir nesse cenário sem cair nas armadilhas da normalização, sem dar força aos discursos de marginalização e incapacitação das pessoas com deficiência.

Law e Mol (1995) salientam que as narrativas têm um papel preponderante nos estudos CTS. Num mundo cuja ontologia é de geometria variável, as narrativas são modos de manejar, de lidar com a multiplicidade de materialidades e socialidades articuladas em um contexto - a lógica, aqui, é a do patchwork (1995, p.288), na qual nos movemos de um lugar para outro, procurando conexões locais, sem a expectativa de um padrão único ou de uma totalidade. Assim, a metodologia é também uma questão de ontologia política: trata-se de definir que realidades seguir. Com este trabalho, não se buscou uma narrativa última e definitiva acerca da cegueira. Melo resume essa afirmação quando comenta:

A ramificação das relações, as lacunas e as incompletudes fazem parte da descrição de como os fenômenos se articulam performando uma rede. A preocupação com a consistência foi deslocada na TAR [teoria ator-rede] porque a ordenação é um processo provisório uma vez que as coisas podem estar ordenadas diferentemente em outro instante (...) a coerência é meramente contingencial, nunca uma essência, aparecendo como efeito de um quadro que se estabilizou por um momento (...) Ao colocar várias histórias, uma ao lado da outra, e ao tecer as costuras entre elas, podemos fazer emergir a diferença pela criação de novas relações, escapando da ditadura do já estabelecido (2007, p.176-177). 
Com isso, perde-se a história global, a visão do todo. Apostamos com Law (1997) que existem outras possibilidades de narrar que não se resumem a uma narrativa totalizante, última e definitiva. Ao fazer proliferar as narrativas locais, menores, parciais, este artigo faz existir multiplicidade das cegueiras. "No caminho, perde-se a grande história. Este é o custo: não temos mais a visão geral. Mas, ao mesmo tempo, criamos algo que não existia antes: interferências entre as histórias [...], cultivar várias histórias uma ao lado da outra é alterar o caráter do saber e do fazer. É tornar o saber e o fazer complexo e múltiplo" (1997, p.3).

A multiplicação das narrativas é um modo de conhecer que se assume a heterogeneidade do real e que, ao mesmo tempo, sublinha-se um processo de seleção daquele que narra, marcando o caráter situado, encarnado, do conhecimento. A esse respeito, Haraway (2007) afirma que o conhecimento é sempre parcial, situado, conhecimento que parte de algum lugar. Para a autora, a visão geral, universal, é um conhecimento de lugar nenhum. Em suas palavras "o único modo de encontrar uma visão mais ampla é estar em algum lugar em particular (Haraway, 2007, p.684)". Assim, o conhecer é algo que ocorre encarnado na heterogeneidade de condições que formam o pesquisador, e ele também é efeito de certo ordenamento de materialidades e socialidades.

Recebido para publicação em dezembro de 2010) (Aceito em janeiro de 2011)

\section{REFERÊNCIAS}

BRASIL. Ministério da Educação. Secretaria de Educação Especial. Programa de capacitação de recursos humanos do ensino fundamental: deficiência visual. 2001. Disponível em: www.dominiopublico.gov.br/download/texto/ me000464.pdf. Acesso em: abr. 2010.

CANGUILHEM, G. El conocimiento de la vida. Barcelona: Anagrama, 1976.

DINIZ, D.; MEDEIROS, M.; SQUINCA, F. Reflexões sobre a versão em Português da Classificação Internacional de Funcionalidade, Incapacidade e Saúde. Cadernos de Saúde Pública, Rio de Janeiro, v.23, n.10, p.2507-2510, 2007

FOUCAULT, M. A arqueologia do saber. Rio de Janeiro: Forense, 1972.
Vigiar e punir: nascimento da prisão. Petrópolis: Vozes, 1987.

Em defesa da sociedade. Curso no Collège de France (1975-1976). São Paulo: Martins Fontes, 2000.

HARAWAY, D. The persistence of vision. In: MIRZOEFF, N. (Ed.) The visual culture reader. New York: Routledge, 2007.

KASTRUP, V.; CARIJÓ, F.; ALMEIDA, M. C. A abordagem da enação no campo da deficiência visual. Informática na Educação: Teoria \& Prática, Porto Alegre, v.12, n.2, jul. dez., 2009.

LATOUR, B. A ciência em ação. São Paulo: Unesp, 1987. 1994. Jamais fomos modernos. Rio de Janeiro: Ed. 34 A esperança de Pandora. Bauru: EDUSC, 2001.

How to talk about the body? 2002. Disponível em: www.ensmp.fr. Acesso em: 2005.

LAW, J. On sociology and STS. The Sociological Review, Reino Unido, United Kingdom, v.56, n.4, p.623-649, 2008.

After method. Mess in social science research. $\overline{\text { London }}$ and New York: Routledge, 2004.

Political philosophy and disabled specificities, 1999. Disponível em: www.comp. lancs.ac.uk/sociology/ papers/Law-Political-Philosophy-and-Disabilities.pdf. Acesso em: 2006.

Aircraft stories. Decentring the object in tenchnoscience. Keele: 1997. mimeo

HASSARD, J. (Ed.) Actor network theory and after. The Sociological Review, London, Blackwell, 1999.

LAW, J.; MOL, A. Notes on materiality and sociality. In: HASSARD, J. (Ed.) Actor network theory and after. The Sociological Review, London, Blackwell, p.274-294, 1995.

LOPES, M. C. B. L.; KITADAI, S. P. S.; OKAI, L. A. Avaliação e tratamento fisioterapêutico das alterações motoras presentes em criancas deficientes visuais. Revista Brasileira. Oftal., Santo Amaro, SP, v.63, n.3, p.155-161, 2004.

LOPES, C.L.R.; BARBOSA, M.A.; MARQUES, E.S.; LINO, A.I.A.;MORAIS, N.H.F. O trabalho da enfermagem na detecção de problemas visuais em criancas/adolescentes. Revista Eletrônica de Enfermagem, Goiânia,GO, v.5 n.2 p.55-59, 2003. Disponível em: www.fen.ufg.br/revista.

MARTINS, B. S. E se eu fosse cego? Narrativas silenciadas da deficiência. Lisboa: Afrontamento, 2006a.

. A cegueira como transgressão corporal: dos corpos marcados aos corpos que marcam, 2006b. Disponíve em:www.apantropologia.net/publicacoes/actascongresso2006/ cap7/Martins Bruno.pdf. Acesso em: 2007.

Políticas sociais na deficiência: exclusões perpetuadas, 2006c. Disponível em: www.ces.uc.pt/ publicacoes/oficina/228/228.pdf. Acesso em: 2007.

MELO, M. F. A. Q. Seguindo as pipas com a metodologia da TAR Revista do Departamento de Psicologia da UFF, Niterói, v.19, n.1, p.169-186, 2007.

MOL, A. The logic of care. Health and the logic of patient care. London: Routledge, 2008.

The body multiple: ontology in medical practice. USA: Duke University Press, 2002

; LAW, J. Embodied action, enacted bodies. The example of hypoglicaemya, 2003. Disponível em: http:// bod.sagepub.com/. Acesso em: 2006.

MORAES, M. PesquisarCOM: política ontológica e defici- 
ência visual. In ; KASTRUP, V. Exercícios de ver e não ver: arte e pesquisa com pessoas com deficiência visual. Rio de Janeiro: Nau, 2010.

; A contribuição da antropologia simétrica à pesquisa intervenção em psicologia social: uma oficina de expressão corporal com jovens deficientes visuais. Psicologia e Sociedade, Brasília, v.20, n.esp., p.41-49, 2008.

Modos de intervir com jovens deficientes visuais: dois estudos de caso. Psicologia Escolar e Educacional, Campinas,SP, ABRAPEE, v.1, p.90-110, 2007.

Ver e não ver: sobre o corpo como suporte da percepção entre jovens deficientes visuais. Revista Benjamin Constant, Brasília, v.12, n.33, p.15-20, 2006.

A ciência como rede de atores: ressonâncias filosóficas. História, Ciências, Saúde-Manguinhos, Rio de Janeiro, v.11, n.2, maio/ago., p.321-333, 2004.

; ARENDT, R. Materialidades e socialidades no cotidiano: múltiplos modos de ordenamento da deficiência visual. In: ; SOUZA, S. J. Tecnologias e modos de ser no contemporâneo. Rio de Janeiro: Ed. 7 Letras/ PUC-RJ, 2010.

; KASTRUP, V. Exercícios de ver e não ver: arte e

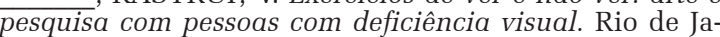
neiro: Nau, 2010

MOSER, I. Disability and the promises of techonology: technology, subjectivity and embodiment within an order of the normal. Information, Comunication and Society, S.l., v.9, n.3, dec. p.370-392, 2006.
On becoming disabled and articulating alternatives. The multiple modes of ordering disability and their interferences. Cultural Studies, Chicago, v.19, n.6, p.667-700, 2005.

Against normalisation: subverting norms of ability and disability. Science as Culture, London, v.9, n.2, p.201-240, 2000

; LAW, J. Making voices: new media technologies, disabilities and articulation, 2001. Disponível em: www.com.lancs.ac.uk/sociology/soc060jl.html. Acesso em: 2007.

NEVES, J. G. Deficiência visual e inclusão: uma análise da política pública em ação. 2010. Monografia (Final de Curso) - Universidade Federal Fluminense, Departamento de Psicologia. Niterói, 2010.

SANTOS, W.R.; DINIZ, D. Deficiência e perícia médica: os contornos do corpo. RECIIS: Revista Eletrônica de Comunicação, Informação \& Inovação em Saúde, Rio de Janeiro, v.3, n.2, p.16-23, jun., 2009.

SÁ, E. D.; CAMPOS, I. M.; SILVA, M. B. C. Atendimento educacional especializado. Formação continuada à distância de professores para o atendimento educacional especializado. Deficiência visual. Brasília: SEESP/SEED/ MEC, 2007.

SILVA, L. O braille e a sua importância na educação dos cegos. 2005. Disponível em: www.lerparaver.com/node/ 146. Acesso em: 2010 


\section{HERE I AM BLIND, THERE I AM SIGHTED: ways of sorting visual impairment and efficiency}

\author{
Marcia Moraes \\ Ronald João Jacques Arendt
}

Situating itself in the field of science, technology and society studies (STS), this paper investigates different ways of ordering visual impairment, that is, the ways in which disability is made in different practices, in a specialized institution. Relevant documents are analyzed in the field of visual impairment and in some cases, allowing one to discuss the concept of disability as a deficit. This paper stresses that the relationship between body and visual impairment should not be summarized to identify the visually impaired with the absence of a sensory function. Through the cases investigated, the authors propose to investigate the visual impairment through a body in action, which is defined by means of connections it establishes with the most disparate elements, human and nonhuman. This paper concludes by pointing out the political relevance of multiplying versions of visual efficiency and impairment, and so to subvert the conception of disability as a deficit.

KEYWORDS: visual impairment, body in action, modes of ordering, materiality, socialities.

\section{AVEUGLE ICI, VOYANTE LÀ-BAS: Les manières d'agencer l'efficience et la déficience visuelle}

\author{
Marcia Moraes \\ Ronald João Jacques Arendt
}

Dans le cadre des études en science, technologie et société (STS), cet article présente une recherche faite sur les différents modes d'agencement de la déficience visuelle, c'est-à-dire sur les manières selon lesquelles la déficience s'exerce au niveau de différentes pratiques, au sein d'une institution spécialisée. Des documents pertinents dans le domaine de la déficience visuelle et quelques cas qui y sont analysés permettent de poser le problème de la conception de la déficience considérée comme un déficit. L’article souligne que la relation entre le corps et la déficience visuelle ne doit pas se résumer à l'identification de la déficience visuelle en tant qu'absence de fonction sensorielle. Á partir des cas étudiés, les auteurs proposent que la recherche sur la déficience visuelle soit faite sur un corps en action qui se définit par le biais des connexions établies entre les éléments, humains et non humains, les plus disparates. La conclusion de ce travail montre l'importance politique de la multiplication des versions d'efficience et de déficience visuelle afin de modifier la conception de déficience considérée comme un déficit.

MOTS-CLES: déficience visuelle, corps en action, agencements, matérialités, socialités.

Marcia Moraes - Doutora em Psicologa Cåínica. Professora do Departamento de Psicologia da Universidade Federal Fluminense.Vice-coordenadora do Programa de Pós-graduação em Psicologia da Universidade Federal Fluminense. Integra o Grupo de Pesquisa Entre_Redes, desenvolvendo pesquisas na área deficiência visual, estudos ciência, tecnologia e sociedade, epistemologia da psicologia. Suas mais recentes publicações, são: MORAES, M.; KASTRUP, V. Exercícios de ver e não ver: arte e pesquisa com pessoas com deficiência visual. Rio de Janeiro: Nau, 2010. SOUZA, J.; MORAES, M. Tecnologias e modos de ser no contemporâneo. Rio de Janeiro: PUC/RJ-7 Letras, 2010. MORAES, M. A contribuição da antropologia simétrica à pesquisa intervenção em psicologia social: uma oficina de expressão corporal com jovens deficientes visuais. Psicologia e Sociedade, v. esp, p. 41-49, 2008.

Ronald João Jacques Arendt - Doutor em Psicologia. Professor do Departamento de Psicologia Social e Institucional da Universidade do Estado do Rio de Janeiro. Integra o Núcleo de Pesquisa Entre_Redes, desenvolvendo pesquisas na área de Psicologia Social. Suas mais recentes publicações, são: MORAES, M.; ARENDT, R. Materialidades e socialidades no cotidiano: múltiplos modos de ordenamento da deficiência visual. In: MORAES, M.; SOUZA, S. J. Tecnologias e modos de ser no contemporâneo. Rio de Janeiro: Ed. 7 Letras/PUCRJ, 2010. ARENDT, R. Enfim: e a tua Psicologia, como é, e para quê? In: FERREIRA, A. A. L, FREIRE, L. MORAES,M.; ARENDT, R. J. J. Teoria Ator-Rede e Psicologia. Rio de Janeiro: Nau Editora., 2010. ARENDT, R. J. J. Maneiras de pesquisar no cotidiano: contribuição da teoria do ator-rede. Psicologia e Sociedade, v. esp, p. 7-11, 2008. 